\title{
An Overview of the Regional Experiments for Land-atmosphere Exchanges 2012 (REFLEX 2012) Campaign
}

Wim J. TIMMERMANS ${ }^{1}$, Christiaan van der TOL $^{1}$, Joris TIMMERMANS ${ }^{1}$, Murat UCER ${ }^{1}$, Xuelong $\mathrm{CHEN}^{1}$, Luis ALONSO${ }^{2}$, Jose MORENO ${ }^{2}$, Arnaud CARRARA ${ }^{3}$, Ramon LOPEZ ${ }^{3}$, Fernando de la CRUZ TERCERO ${ }^{4}$, Horacio L. CORCOLES ${ }^{4}$, Eduardo de MIGUEL ${ }^{5}$, Jose A.G. SANCHEZ ${ }^{5}$, Irene PÉREZ ${ }^{5}$, Belen FRANCH ${ }^{6}$, Juan-Carlos J. MUNOZ ${ }^{6}$, Drazen SKOKOVIC ${ }^{6}$, Jose $\mathrm{SOBRINO}^{6}$, Guillem SORIA ${ }^{6}$, Alasdair MacARTHUR ${ }^{7}$, Loris VESCOVO ${ }^{8}$, Ils REUSEN ${ }^{9}$, Ana ANDREU ${ }^{10}$, Andreas BURKART ${ }^{11}$, Chiara CILIA ${ }^{12}$, Sergio CONTRERAS ${ }^{13}$, Chiara CORBARI ${ }^{14}$, Javier F. CALLEJA ${ }^{15}$, Radoslaw GUZINSKI ${ }^{16}$, Christine HELLMANN ${ }^{17}$, Ittai HERRMANN ${ }^{18}$,

Gregoire KERR ${ }^{19}$, Adina-Laura LAZAR ${ }^{20}$, Benjamin LEUTNER ${ }^{21}$, Gorka MENDIGUREN ${ }^{13}$, Sylwia NASILOWSKA ${ }^{22}$, Hector NIETO ${ }^{16}$, Javier PACHEGO-LABRADOR ${ }^{13}$, Survana PULANEKAR ${ }^{23}$, Rahul RAJ ${ }^{1}$, Anke SCHIKLING ${ }^{11}$, Bastian SIEGMANN ${ }^{24}$, Stefanie von BUEREN ${ }^{25}$, and Zhongbo (Bob) $\mathrm{SU}^{1}$

${ }^{1}$ University of Twente, Faculty of Geo-information Science and Earth Observation, Department of Water Resources, Enschede, The Netherlands e-mail: w.j.timmermans@utwente.nl (corresponding author)

${ }^{2}$ Laboratory for Earth Observation, Department of Earth Physics, University of Valencia, Valencia, Spain

${ }^{3}$ Fundacion CEAM, Parque Tecnologico, Valencia, Spain

${ }^{4}$ Instituto Técnico Agronómico Provincial de Albacete (ITAP), Albacete, Spain

${ }^{5}$ Instituto Nacional de Tecnica Aerospacial (INTA), Depto. De Observacion de la Tierra, Teledeteccion y Atmosfera, Madrid, Spain

${ }^{6}$ Global Change Unit (GCU), Department of Earth Physics, University of Valencia, Valencia, Spain 
${ }^{7}$ NERC Field Spectroscopy Facility, University of Edinburgh, Edinburgh, United Kingdom

${ }^{8}$ Fondazione Edmund Mach-Research and Innovation Centre, San Michele all'Adige, Trento, Italy

${ }^{9}$ Flemish Institute for Technological Research (VITO), Mol, Belgium

${ }^{10}$ Instituto de Investigación y Formación Agraria y Pesquera (IFAPA), Sevilla, Spain

${ }^{11}$ Institute of Bio- and Geosciences, IBG-2: Plant Sciences, Forschungszentrum Jülich, Jülich, Germany

${ }^{12}$ University Milano Bicocca, Milano, Italy

${ }^{13}$ Consejo Superior de Investigaciones Científicas (CSIC), Madrid, Spain

${ }^{14}$ Politecnico di Milano, Milano, Italy

${ }^{15}$ University of Oviedo, Oviedo, Spain

${ }^{16}$ University of Copenhagen, Copenhagen, Denmark

${ }^{17}$ Experimental and Systems Ecology, University of Bielefeld, Bielefeld, Germany

${ }^{18}$ The Remote Sensing Laboratory, Jacob Blaustein Institutes for Desert Research,

Ben-Gurion University of the Negev, Beer-Sheva, Israel

${ }^{19}$ German Aerospace Center (DLR), Oberpfaffenhofen, Wessling, Germany

${ }^{20}$ Babes-Bolyai University, Cluj-Napoca, Romania

${ }^{21}$ University of Würzburg, Würzburg, Germany

${ }^{22}$ University of Warsaw, Warsaw, Poland

${ }^{23}$ University of Reading, Reading, United Kingdom

${ }^{24}$ University of Osnabruck, Osnabruck, Germany

${ }^{25}$ Massey University, Palmerston North, New Zealand

\section{Abstract}

The REFLEX 2012 campaign was initiated as part of a training course on the organization of an airborne campaign to support advancement of the understanding of land-atmosphere interaction processes. This article describes the campaign, its objectives and observations, remote as well as in situ. The observations took place at the experimental Las Tiesas farm in an agricultural area in the south of Spain. During the period of ten days, measurements were made to capture the main processes controlling the local and regional land-atmosphere exchanges. Apart from multi-temporal, multi-directional and multi-spatial space-borne and airborne observations, measurements of the local meteorology, energy fluxes, soil temperature profiles, soil moisture profiles, surface temperature, canopy structure as well as leaf-level measurements were carried out. Additional thermo-dynamical monitoring took place at selected sites. 
After presenting the different types of measurements, some examples are given to illustrate the potential of the observations made.

Key words: land-atmosphere interaction, multi-scale heterogeneity, turbulence, calibration and validation, quantitative remote sensing.

\section{INTRODUCTION}

Quantification of bio-geophysical variables of different surfaces is essential for understanding the earth system and for the development of earth system models for prediction of climate and environmental change (Kornelsen and Coulibalya 2013, Mishra and Singh 2011, Rast et al. 2014, Seneviratne et al. 2010, Wang and Dickinson 2012). Remote sensing monitoring is essential for the development and validation of these observational and process models as well as retrieval algorithms (Gamon et al. 2010, Rodell et al. 2004, Salama et al. 2012, van Dijk and Renzullo 2011, Yebra et al. 2013).

Understanding the retrieval of bio-geophysical variables from opticalthermal and microwave data and the modeling of the underlying processes over inhomogeneous terrain remains problematic due to a lack of observational data at appropriate scales (McCabe and Wood 2006, Timmermans et al. 2008, 2013, Wu and Li 2009). Thereto a campaign was designed to use airborne sensors for multi-angular hyper-spectral optical-thermal data acquisition and to collect field measurements over several land-cover units. In addition, optical-thermal satellite data for the same period were acquired. The obtained data-set was then used for model validation and inversion algorithms that are used to extract quantitative surface variables and for landatmosphere interaction studies.

To advance the understanding of land-atmosphere exchanges of water and heat at spatial and temporal scales, measurements of these exchanges and of thermo-dynamic states of the atmosphere and surface were carried out over several land-cover units. Since turbulent fluxes occur from molecular to regional scales and are influenced by internal biophysical characteristics and external forcing (e.g., solar radiation and wind), the measurements of these fluxes are very challenging over a heterogeneous terrain (Novick et al. 2014, Prueger et al. 2012). Because the terrain heterogeneity (in terms of surface roughness and soil and vegetation properties) in combination with the turbulent fluxes causes thermo-dynamic changes of the surface state, a number of ground based instruments is employed. These were distributed over several different land-cover units to ensure a complete observation and understanding of these fluxes at spatial and temporal scales.

The campaign was carried out under the umbrella of the REFLEX 2012 training course supported by the FP7-funded European Facility For Airborne Research (EUFAR) and Cost Action-funded ES0903 EUROSPEC projects 
and took place in Albacete and Barrax, Spain, during 18 to 28 July 2012. The theme of the course was the organizing and conducting of a hyperspectral multi-angular airborne campaign in the framework of multi-scale ("leaf-to-ecosystem") land-atmosphere exchange research.

\section{MAIN OBJECTIVES AND TASKS OF THE CAMPAIGN}

The general objectives of the campaign were:

a advancement of the process understanding that describes radiative and turbulent transfer in land-atmosphere interactions,

- acquisition of simultaneous multi-temporal, multi-angular, and multi-sensor hyper-spectral data over a heterogeneous area,

- validation of bio-geophysical variables extraction from satellite data using airborne and in situ data,

- improvement of soil moisture retrieval by using both multi-angular and hyper-spectral optical-thermal observations.

To reach these objectives, a specific tailor-made flight plan was designed concurrent to field measurements supporting the airborne data processing and analysis. To ensure the availability of multi-angular and multi-scale optical-thermal observations, satellite data, comprising Compact High Resolution Imaging Spectrometer - Project for On-Board Autonomy (CHRISPROBA) and Meteosat Second Generation (MSG), were collected during the campaign as well. The CASA 212-INTA airplane was used for mounting the Airborne Hyperspectral Scanner (AHS) and Compact Airborne Spectrographic Imager (CASI) sensors in order to collect multi-sensor hyperspectral data and a flight plan was developed so as to ensure multi-angular and multi-temporal observations at high spatial resolution.

Information of the atmospheric state, which mainly concerns the Aerosol Optical Thickness (AOT), the ozone and water vapour content, is needed to carry out atmospheric corrections of spaceborne and airborne measurements. Several types of atmospheric and field-based observations supporting this were obtained simultaneously, comprising atmospheric soundings as well as in situ measurements using sun photometers. Different groups were simultaneously operating Analytical Spectral Devices (ASD) FieldSpec Pro FR, CIMEL, and Everest radiometers for measuring reflectance and emittance from calibration targets in the solar and thermal range of the electromagnetic spectrum.

Knowledge of the heat transfer, needed for understanding the exchanges of water vapour and energy between a canopy and the surrounding atmosphere, was obtained in several ways, depending on the scale. Locally this involved the monitoring of individual leaf and soil sunlit and shadowed temperatures, whereas more towards a regional scale, micro-meteorological 
and turbulent flux measurements were carried out from masts at specific selected sites. These comprised Eddy-Covariance (EC) and Large Aperture Scintillometer (LAS) measurements, covering multiple land-cover units, in combination with profile observations of specific humidity, air temperature and windspeed, and profiles of soil temperature, soil heat flux, and soil moisture.

Finally, a limited number of field-based biophysical (soil, vegetation, and water) measurements were carried out over different land-cover units. Among other things, they comprised the estimates of Fractional Vegetation Cover (FVC), Leaf Area Index (LAI), Photosynthetically Active Radiation (PAR), leaf reflectance, leaf transmittance, surface emissivity, and soil moisture.

\section{EXPERIMENT AND DATASETS}

\subsection{Experimental site and background climatology}

The campaign area was the well-known Barrax test site, situated at a plateau $700 \mathrm{~m}$ a.s.l. within the La Mancha region, in the south-east of Spain (Fig. 1). The agricultural area is located in the west of the Albacete province, $20 \mathrm{~km}$ from the capital town Albacete.

The area is characterized by a flat morphology and large, uniform land use units and consists of approximately $65 \%$ of dry land, and $35 \%$ of irri-

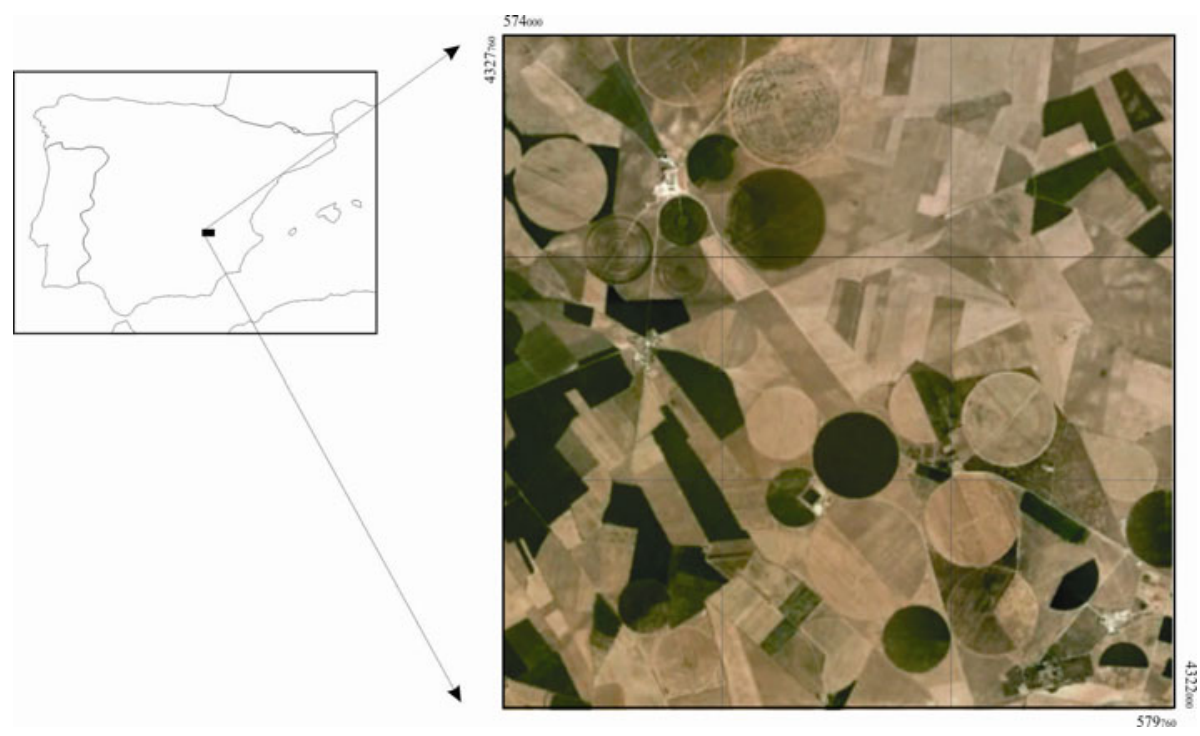

Fig. 1. Site location (zoom from Google Earth). 
gated land with different agricultural crops and orchards. Field sizes range from a few tens of meters up to almost $1 \mathrm{~km}$ in diameter, where the larger fields are circular shaped and irrigated by a rotating pivot system.

The majority of the campaign activities were concentrated in the fields of the Las Tiesas experimental farm, operated by the Instituto Tecnico Agronomico Provincial (ITAP) of Albacete, Spain, which has been used extensively in previous campaigns for calibration and validation of remote sensing observations (Sobrino et al. 2009, Su et al. 2008). A landcover map for the Las Tiesas fields is digitally available. The main land use types during the current campaign included: bare soil, vineyard, maize, forest nursery, barley (stubble), wheat (stubble), poppy, (young) sunflower, walnut and pistachio orchards, and camelina (from the mustard family). At the time of the campaign, most of the crops were already harvested. The only canopies with a significant green vegetation fraction during the campaign were maize, vineyard, and sunflower (early growth stage) as well as orchards and forest nursery.

The La Mancha region has a mid-latitude semi-arid climate with most of the rainfall concentrated during the spring and autumn seasons, and lower levels during the summer. With an annual rainfall which averages around $350 \mathrm{~mm}$, La Mancha is one of the driest regions of Europe and potential evaporation rates reach up to $900 \mathrm{~mm}$ per year. Due to these dry conditions combined with intensive irrigation practices the regional water table is about 20-30 $\mathrm{m}$ below the land surface.

The area is characterized by cold winters and hot dry summers. Monthly averages of minimum temperature range from $2{ }^{\circ} \mathrm{C}$ in January to $19{ }^{\circ} \mathrm{C}$ during July, whereas monthly maximum temperatures range from $11^{\circ} \mathrm{C}$ to $34{ }^{\circ} \mathrm{C}$ in these months. During the summer months, temperatures above $40^{\circ} \mathrm{C}$ are not uncommon and rainfall is rare.

\subsection{Remote sensing data acquisitions}

\section{Satellite data acquisitions}

To comply with the multi-directional, multi-temporal, and multi-spatial character of the land-atmosphere exchange experiment undertaken, spaceborne observations from two specific platforms were acquired during the campaign. The multi-temporal aspect was covered by the acquisition of MSG observations every 15 min during the entire campaign at a low spatial resolution of $3 \mathrm{~km}$, whereas the multi-directional aspect was covered by acquiring Compact High Resolution Imaging Spectrometer (CHRIS) data at a relatively high spatial resolution of $36 \mathrm{~m}$.

CHRIS is a small and relatively light (weight less than $15 \mathrm{~kg}$ ) spectrometer and it operates in push-broom mode. Its main application areas are in for- 
estry, environmental monitoring and precision farming. Its orbit is at $600 \mathrm{~km}$, which results in a $14 \mathrm{~km}$ swath with a spatial resolution of $18 \mathrm{~m}$. This is slightly variable because the altitude varies along the orbit. CHRIS is mounted on the PROBA (PRoject for On-Board Autonomy) platform, which has steering capabilities in the along- and across-track directions. This enables observation of selectable targets far outside the nominal field of view of $1.3^{\circ}$. Images are generally acquired in sets of 5, taken at along track angles of \pm 55 degrees, \pm 36 degrees, and at nadir (see Fig. 2).

CHRIS operates in the visible to near infrared wavelength region (400 to $1050 \mathrm{~nm}$ ) and can either operate in 63 spectral bands at a reduced spatial resolution of $36 \mathrm{~m}$, or with 18 bands at full spatial resolution. Its spectral resolution is variable from $2-3 \mathrm{~nm}$ at the blue end of the spectrum, to some $12 \mathrm{~nm}$ at the $1050 \mathrm{~nm}$ edge. As such, the instrument is very flexible and different sets of bands and configurations can be used for different applications.

The Meteosat Second Generation 1 (MSG1) satellite, renamed Meteosat-8, carries the Spinning Enhanced Visible and Infrared Imager (SEVIRI) which is its main payload. This optical imaging radiometer consists of three visible and near infrared channels, eight infrared channels, and one visible broadband channel called the High Resolution Visible channel (HRV). The spatial resolution of SEVIRI channels is $3 \mathrm{~km}$ at sub-satellite point, except for the HRV channel which has a $1 \mathrm{~km}$ resolution. The temporal resolution is $15 \mathrm{~min}$. The data acquisition for the period of the campaign was standard and the imagery is freely available. For downloading the data the following link from the Unified Meteorological Archive and Retrieval Facility (UMARF) is recommended: http://www.eumetsat.int/Home/Main/Data Access/EUMETSATDataCentre/index.htm?1=en where one should select: "High Rate SEVIRI Level 1.5 Image data" and select "HRIT data sets in tar

(a)

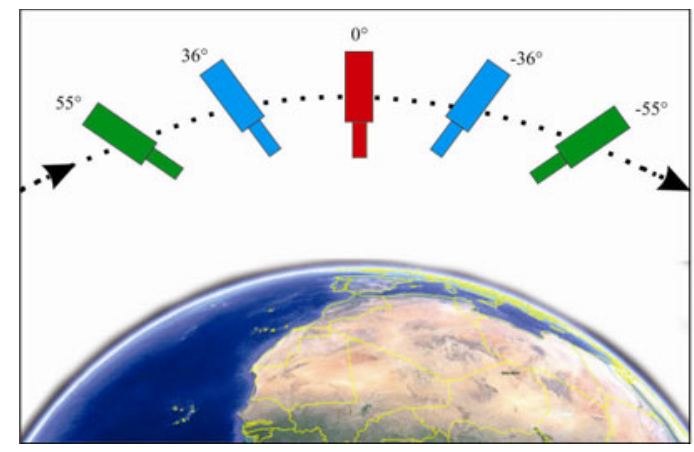

(b)

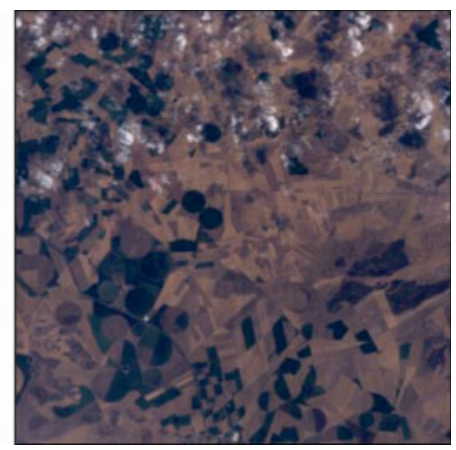

Fig. 2. Illustration of how CHRIS can hold a target in view by using PROBA's pitch control (a) and nadir view of CHRIS-PROBA acquisition over the Barrax site on 22 July 2012, 07:56 UTC (b), channels 23-9-5 for RGB. 
Table 1

Overview of the space- and air-borne observations

\begin{tabular}{|l|c|c|c|c|c|}
\hline Sensor & $\begin{array}{c}\text { Number of } \\
\text { channels }\end{array}$ & $\begin{array}{c}\text { Spectral range } \\
{[\mu \mathrm{m}]}\end{array}$ & $\begin{array}{c}\text { Resolution } \\
{[\mathrm{m}]}\end{array}$ & $\begin{array}{c}\text { Acquisition } \\
\text { date }\end{array}$ & $\begin{array}{c}\text { Acquisition } \\
\text { DOY }\end{array}$ \\
\hline MSG & 12 & $0.60-14.40$ & $1000 / 3000$ & 18-28 July 2012 & $200-210$ \\
CHRIS & 63 & $0.40-1.05$ & 36 & 22 July 2012 & 204 \\
AHS & 80 & $0.43-12.70$ & $2.1 / 3.9$ & 25/26 July 2012 & $207-208$ \\
CASI & $144 / 288$ & $0.38-1.05$ & $0.48 / 0.98$ & 25/26 July 2012 & $207-208$ \\
\hline
\end{tabular}

file" to receive HRIT files. Background information and the freeware to process the data is available at: http://52north.org/communities/earthobservation/ about-geonetcast. An overview of the sensor characteristics of the satellite and airborne observations is provided in Table 1.

\section{Airborne data acquisitions}

Two airborne sensors have been operated during the REFLEX 2012 campaign to acquire important data for bio-geo-physical variable estimation over the Barrax site. The Airborne Hyperspectral Scanner (AHS) and Compact Airborne Imaging Spectrometer (CASI) sensors were mounted on the CASA 212-200 N/S 270 "Paternina" airplane of INTA. Because the campaign was primarily aiming at land-atmosphere interactions, the thermal observation capacities of the AHS sensor were prioritized. Therefore, the flight configuration was designed such that if conflicting criteria between AHS and CASI occurred, preference was given to AHS.

With respect to the timing of the airborne data acquisitions, there were no constraints with respect to linking the acquisitions to simultaneous satellite overpasses; the CHRIS-PROBA overpass fell outside the possible window for airborne acquisitions due to the unavailability of the airplane, whereas the MSG acquisitions have a frequency much higher than an airborne acquisition window (typically one hour or more).

From a scientific viewpoint it was desirable to obtain at least one nighttime acquisition in order to determine thermal inertia. Thermal inertia is highly correlated with soil/canopy moisture content and as such of major importance for land-atmosphere flux exchanges. Other aspects in the flight line design were the need for multiple viewing angles and the need to cover a full daily cycle. The first objective resulted in flight lines that had a considerable overlap (see Fig. 3). The second objective resulted in planning for a daytime flight, followed by a night-time flight, immediately followed by another daytime flight the next afternoon.

Weather conditions were such that the window of 25 and 26 July was chosen for acquiring the airborne data. The flight lines were then designed to 
(a)

(b)
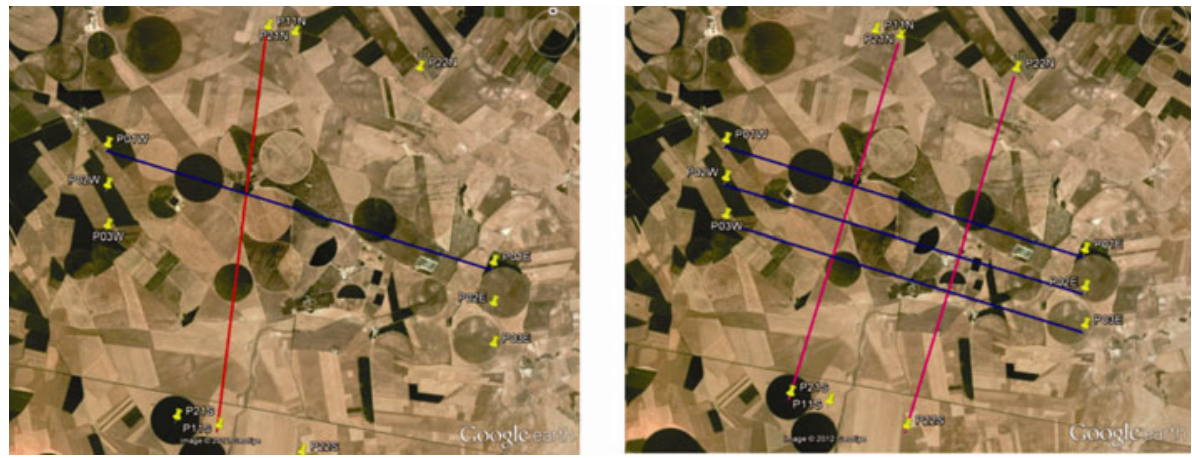

Fig. 3: (a) the flight pattern for the low (1000 m a.g.l.) flights; (b) the flight pattern for the high (2000 m a.g.l.) flights (presented on Google Earth).

match the selected calibration/validation sites as well as the flux observation sites.

The first flight was on Wednesday, 25 July 2012. Weather conditions: some high clouds, and southern wind with a variable intensity. Data acquisition started at 08:41 UTC (10:41 local time). Two lines are performed over the test site at $1000 \mathrm{~m}$ a.g.l., resulting in a high spatial resolution, and five more lines are covered at an altitude of $2000 \mathrm{~m}$ a.g.l., resulting in a reduced resolution (Table 1). Data acquisition was completed at 09:47 UTC (11:47 local time). The second flight was a night flight and took place on the same day. Weather conditions: clear skies. Data acquisition started at 21:30 UTC (23:30 local time) and was completed at 22:41 UTC (00:41 local time).

The third flight took place on Thursday, 26 July 2012, when weather conditions were: clear skies with a south-eastern wind. Data acquisition started at 08:42 UTC (10:42 local time) and was completed at 09:38 UTC (11:38 local time). The flight lines for the second and the third flights were similar to the first flight with the exception of lines P02 and P03 (see Fig. 3), which were skipped since the multi-directional aspect was covered during the first flight. Additional details of the flight lines (timing, exact location) are provided in the flight report, which is present in the REFLEX 2012 database.

The Airborne Hyper-spectral Scanner (AHS) is a linescanner with a concept shared with classical airborne linescanners, similar to the well-known HyMap instrument. The INTA AHS sensor has 63 bands in the reflective part of the electromagnetic spectrum, 7 bands in the 3 to 5 microns range and 10 bands in the 8 to 13 microns region. The Instantaneous Field Of View (IFOV) equals $2.5 \mathrm{mrad}$, and the Field Of View (FOV) is $90^{\circ}$. This resulted in a resolution of 2.1 and $3.9 \mathrm{~m}$ at the low and high altitude flights, respectively. 
The CASI sensor is a pushbroom imager based on a bidimensional Charge Coupled Device (CCD); the instrument measures the incoming radiance along up to 1500 spatial pixels "across-track" in up to 288 separate spectral bands. The spectral bands can be placed anywhere within a $\sim 680 \mathrm{~nm}$ spectral range, which itself can be placed anywhere between 380 and $1050 \mathrm{~nm}$. The CASI is thus sensitive to wavelengths in the visible part of the electromagnetic spectrum, as well as in the near infrared. In the current campaign the settings were such that 144 spectral bands were used, covering the full range from 0.38 to $1.05 \mu \mathrm{m}$ during the high altitude flights, whereas for the low flights the full spectral resolution was used, resulting in 288 spectral bands. The FOV is $40^{\circ}$ and IFOV is $0.5 \mathrm{mrad}$, thus potentially providing a spatial resolution 5 times better than AHS at the same flight altitude. In the current setting this resulted in a spatial resolution of 0.48 and $0.98 \mathrm{~m}$ at the low and high altitude flights, respectively.

\subsection{In situ measurements}

\section{Atmospheric data acquisitions}

Knowledge of the atmospheric conditions, especially the ozone and water vapor content, as well as their vertical profiles is required to perform accurate atmospheric corrections of the space and airborne observations. Two types of measurements are available during this campaign: routinely collected atmospheric soundings and in situ ground-based atmospheric measurements.

Though remote (some 150 from the area), atmospheric soundings from Murcia and Madrid are typical for atmospheric conditions on site, depending on wind directions. When eastern winds are prevailing, typical on-site conditions usually resemble atmospheric characteristics as recorded over Murcia. Under western winds the Madrid conditions prevail in the study area. These soundings are carried out twice daily and for the days of airborne overpasses these soundings are available in the database. They contain profiles of pressure, air temperature, dewpoint, relative humidity, mixing ratio, wind direction, windspeed, potential air temperature, and virtual potential air temperature (Fig. 4).

In addition, in situ atmospheric measurements were carried out at several selected sites using microtops sunphotometers. The instruments were configured to measure the total water vapor column and aerosol optical thickness at $500 \mathrm{~nm}$. These measurements, carried out by several teams on a continuous basis throughout the airborne overpasses, were made in conjunction with radiometric characterization observations at these selected sites. They are described in more detail in the next section. 

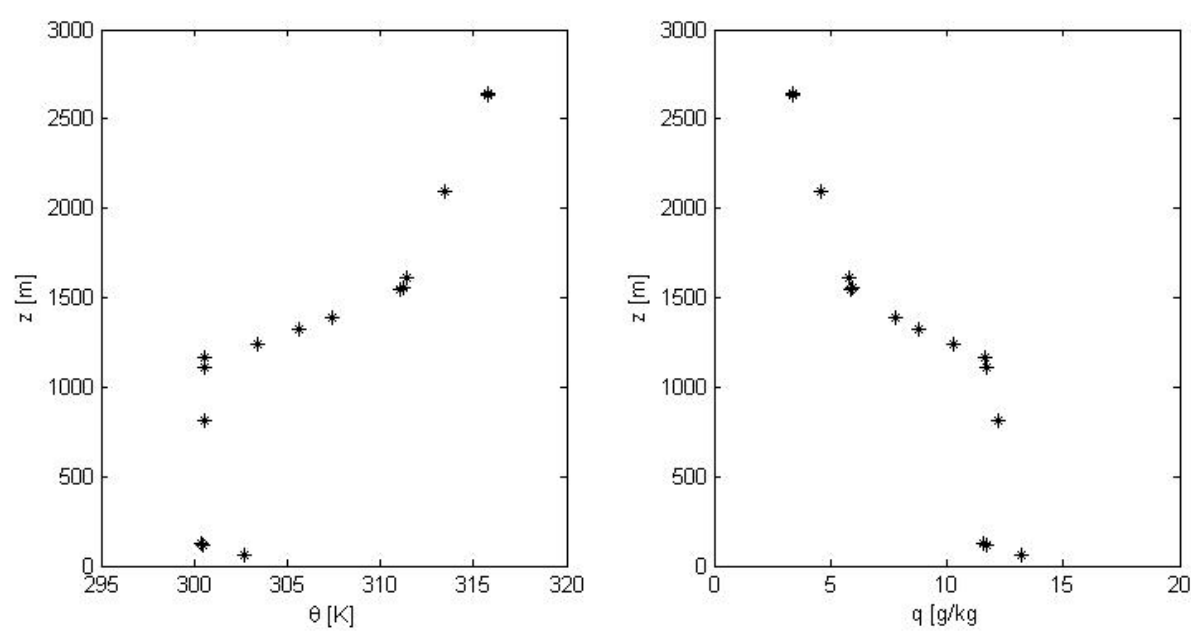

Fig. 4. Madrid mid-day sounding for 26 July 2012, showing profiles of potential temperature, $\theta[\mathrm{K}]$, and specific humidity, $q[\mathrm{~g} / \mathrm{kg}]$.

\section{Radiometric measurements}

Several ground radiometric measurements were carried out at different selected sites. They mainly comprised near-ground spectroscopy, so-called solar range radiometric measurements and thermal infrared radiometric measurements. The sites were selected based on homogeneity at a sufficiently large scale and representativeness of the main land-cover units. In addition, they should show a sufficiently large spread in reflective and emissive behavior and ideally also cover the flux observation sites. An overview of the different locations of these measurements is shown in Fig. 5, where also the flux tower sites and the reference meteorological stations are shown.

Near-ground spectroscopy was carried out for calibration and validation purposes at 5 selected sites comprising grass, wheat stubble, maize, camelina, and vineyard. At these sites, detailed Bidirectional Reflectance Distribution Functions (BRDFs), calibration reflectance and irradiance measurements were carried out as well as observations of atmospheric optical thickness and water vapor content and hemispherical sky photos. At a number of additional sites, comprising bare soil, poppy, wheat stubble, black fabric, grass, and open water calibration reflectance measurements were carried out as well.

Radiometric measurements in the thermal infrared region were also carried out with various instruments that included fixed Field Of View (FOV) and single band as well as multi-band radiometers. In addition, black bodies (calibration sources) for calibrating the instruments were used. These measurements, which aimed at calibrating and validating the thermal air-borne 


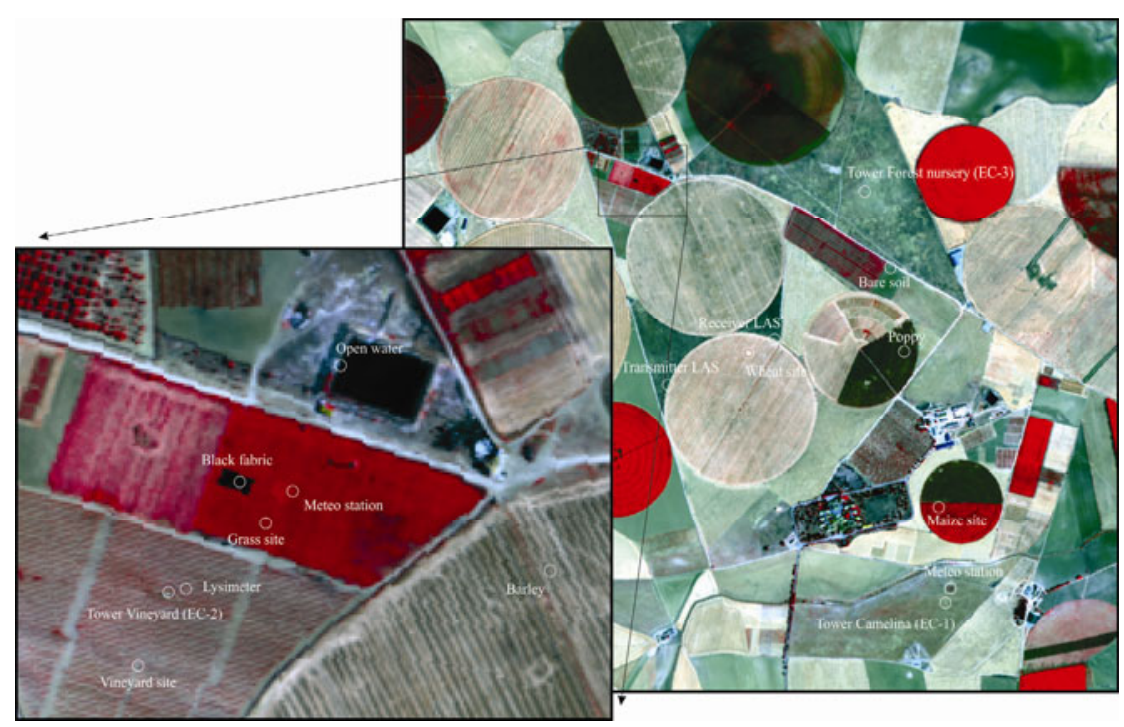

Fig. 5. Overview of the main ground observation location; background image is a false color composite of AHS channels 15-8-4 (RGB) of the 25 July morning overpass. The zoom is on the grassland super site central in the area, where a high concentration of ground observations took place.

observations, consisted of transects which were carried out concurrently to the overpasses of AHS/CASI. They consisted of temperature measurements with different field radiometers (CIMEL, RAYTEK, OPTRIS, and EVEREST), at regular steps of $3 \mathrm{~m}$ over different land covers. These comprised grass, barley stubble, alfalfa, forest nursery, bare soil, wheat stubble, vineyard, poppy, maize, and open water. The data was acquired in a period of time centered around the flight overpasses. The data was then processed following the so-called Temperature and Emissivity Separation (TES) algorithm (Gillespie et al. 1998) to obtain Land Surface Temperature (LST) and surface emissivity.

\section{Biophysical measurements}

Biophysical measurements consisted of the collection of Leaf Area Indices (LAI), Leaf Angle distribution, fraction of Absorbed Photosynthetically Active Radiation (fAPAR) and soil moisture, as well as leaf-level measurements of fluorescence, water, and nitrogen content. For the fluorescence measurements, use has been made of the Pulse-Amplitude Modulated (PAM) method as well as by the so-called leaf-clip, developed by the Laboratory for Earth Observation of the University of Valencia, whereas leaf water- and nitrogen-content analyses were carried out at the David J. Bonfil Laboratory at the Gilat agricultural research center, Israel. The measure- 
ments, which were basically limited to the maize and, partly, sunflower fields, were carried out at several selected plots within the fields. The plots were selected in order to cover the slightly wider range of canopy heights, fAPAR and LAI of the maize field, due to non-homogeneous irrigation, terrain morphology, and soil texture. Data acquisition took place at days 25, 26, and 27 July 2012.

Top-of canopy fAPAR measurements were performed at the plots, by means of a SSI Sunscan Delta-T system. In addition to these top-of-canopy fAPAR observations, incident PAR measurements were carried out at $0.25 \mathrm{~m}$ intervals throughout the canopy to characterize the fAPAR profile in the canopy.

\section{Thermo-dynamic measurements}

The architecture of most of the vegetation canopies leads to a complex threedimensional exchange of heat requiring temperature measurements of the different canopy and soil components at a very local scale. Therefore, a MIDAC thermal range hyper-spectral Fourier Transform Infrared Spectrometer (FTIR) spectrometer was employed along with sensors such as a ThermoTracer thermal camera and thermal radiometers. The ThermoTracer was mounted on a tripoid to acquire daytime-cycle, very high spatial and temporal resolution observations, which were calibrated versus a gold plate with well-known emissivity and temperature. As such, these sensors monitored the temperatures of different land surface components (shadowed versus sunlit, leafs versus soil) on a continuous basis. These component temperatures might then be implemented into a canopy model for the simulation of directional temperatures.

\section{Surface energy budget and micrometeorological measurements}

Measurements of boundary layer heat and moisture fluxes, carbon fluxes, high resolution (in a spectral, spatial, and temporal sense) thermal radiation and other relevant meteorological variables were continuously logged from 16 to 28 July 2012. The objective of the collection of this type of data was to facilitate the modeling of heat, water, and carbon transfer inside and above the canopy, as well as above bare soil. Several characteristic areas were carefully selected, which resulted in the installation of three Eddy Covariance (EC) flux-towers: one over a camelina field, one over the vineyard, and another over the main reforestation area (see Fig. 5 for their respective locations). In addition, a Large Aperture Scintillometer (LAS) was installed over a wheat-stubble field, whereas two reference meteorological stations were continuously storing relevant meteorological variables over the grassland super site and the camelina as well. An overview of the instrumentation used at the flux sites is provided in Table 2 . 
Instrumentation overview of the flux sites

\begin{tabular}{|c|c|c|c|c|}
\hline System & EC-1 & $\mathrm{EC}-2$ & EC-3 & LAS \\
\hline Landcover & Camelina & Vineyard & Forest nursery & Wheat \\
\hline Canopy height & 0.50 & 2.00 & 1.00 & 0.15 \\
\hline Scintillometer & & & & 2.18 \\
\hline 3-D Sonic & $1.30,2.38,5.20$ & 5.70 & 5.00 & \\
\hline $\mathrm{H}_{2} \mathrm{O}$ & 2.38 & 5.70 & 5.00 & \\
\hline $\mathrm{CO}_{2}$ & 2.38 & & 5.00 & \\
\hline Rel. Hum. & $1.30,2.20,4.10$ & $2.50,3.50,5.00$ & $1.45,2.50,4.00$ & 2.18 \\
\hline Air temperature & $1.30,2.20,4.10$ & $2.50,3.50,5.00$ & $1.45,2.50,4.00$ & 2.18 \\
\hline Net radiometer & 1.00 & 4.00 & & \\
\hline Surface temperature & & & 4.00 & \\
\hline Soil heat flux & $-0.08,-0.13$ & -0.02 & -0.10 & -0.13 \\
\hline Soil moisture & $-0.05,-0.10,-0.20$ & & -0.10 & \\
\hline Soil temperature & $\begin{array}{l}-0.01,-0.02,-0.04, \\
-0.08,-0.16,-0.32\end{array}$ & -0.025 & & \\
\hline $\begin{array}{l}\text { Wind speed } \\
\text { Air pressure }\end{array}$ & 180 & $2.50,3.50,5.00$ & $1.45,2.50,4.00$ & 1.85 \\
\hline
\end{tabular}

At these so-called flux sites, continuous monitoring took place of the main components that determine the surface energy budget:

$$
R_{N}=G_{0}+H+\lambda E,
$$

where $R_{N}$ represents the net radiation, $G_{0}$ the surface soil heat flux, $H$ the sensible heat flux, and $\lambda E$ the latent heat flux (all in $\mathrm{W} \cdot \mathrm{m}^{-2}$ ). At the scintillometer site, however, no net radiation and latent heat flux was measured, whereas at the forest nursery site, for net radiation, only the outgoing longwave component was monitored. An example is shown in the top panel of Fig. 6, where the four fluxes are plotted for a larger part of the campaign at the camelina site.

Profile measurements of meteorological variables (relative humidity, air temperature, windspeed, and at selected places wind direction) were carried out at all sites, for which the humidity and temperature sensors were intercalibrated to ensure a sufficiently high accuracy. Windspeed at higher levels was clearly showing higher values than at lower levels, as may be expected. During daytime, when typically strongly unstable atmospheric conditions prevailed, the lower temperature sensors showed higher responses, whereas the opposite was noted for the humidity sensors. During the night, characterized by stable atmospheric conditions, the lower temperature sensors at most 

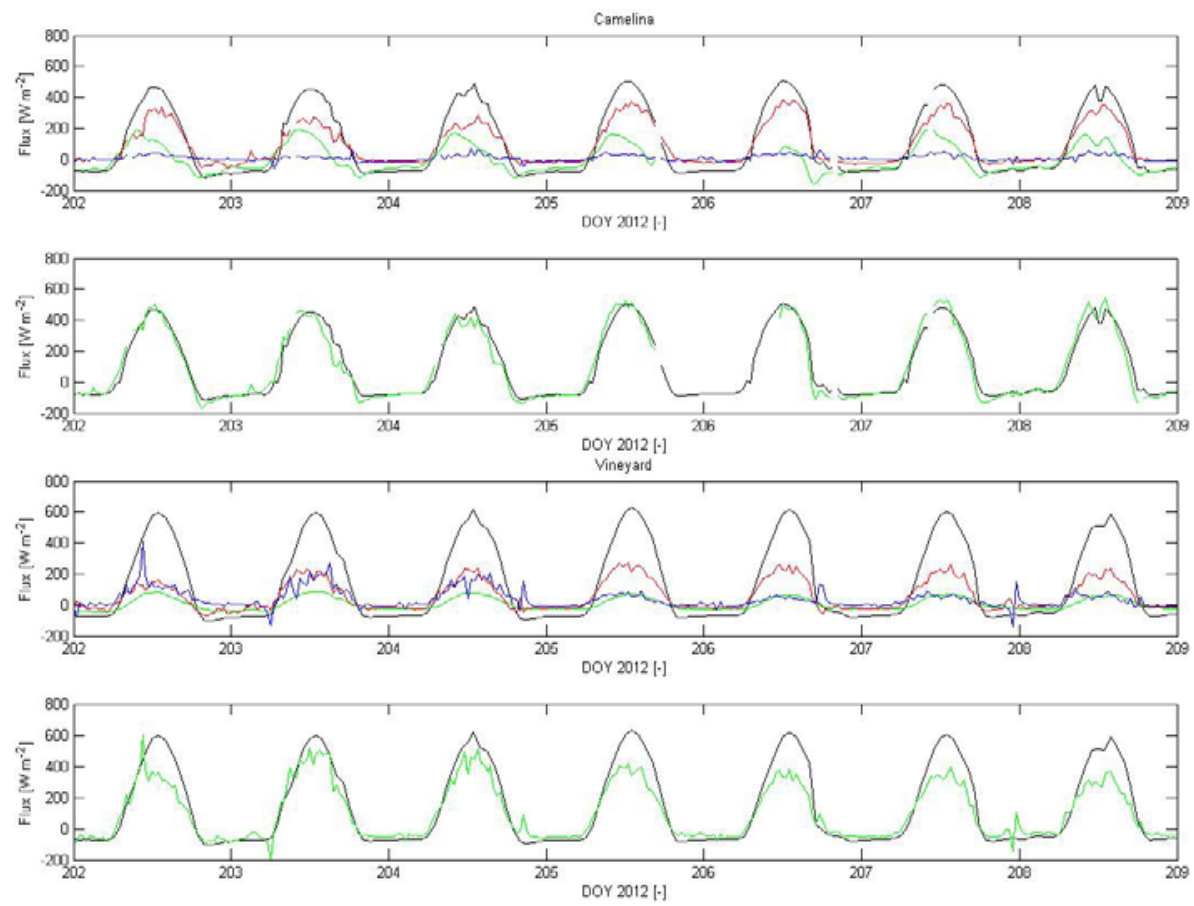

Fig. 6. Surface energy budget components $\left(R_{N}\right.$ in black, $G_{0}$ in green, $H$ in red, and $L E$ in blue) measured during the campaign period. In the second and fourth panel the sum of the components is represented in green.

times recorded lower temperatures, but differences were significantly smaller than during daytime.

Soil moisture and soil temperature observations, needed for postprocessing the soil heat fluxes (van der Tol 2012), were obtained at several depths as well. Typically, the largest daily fluctuations were noticed close to the surface, whereas a damping and delay effect is noticed further away from the surface.

In the second panel of Fig. 6 the net radiation is plotted versus the sum of soil and turbulent fluxes, i.e., sensible and latent heat flux, to examine the well-known energy closure issue (Foken 2008) over the camelina site. In this site, the closure is quite good throughout the campaign, which might be attributed to the very low values of one of the turbulent fluxes (the latent heat flux). However, at certain moments the sum of the soil and turbulent fluxes is slightly larger than the net radiation. This is attributed to the correction procedure necessary to convert soil heat flux from the measured depth to the surface value. Details on this procedure and a discussion of the obtained results are provided in van der Tol et al. (2015). 
The closure over the vineyard site is considerably poorer. This is shown in the lower two panels of Fig. 6, where in the third panel from the top the four individual fluxes are shown, and in the lowest panel the net radiation and the sum of the soil, sensible and latent heat flux.

It is noted that the measured net radiation, especially during daytime conditions, is consistently higher than the sum of the components. This is attributed to the fact that the field of view of the net radiometer was dominated by canopy, resulting in a relatively low albedo and thus high net radiation. Another striking feature is that starting on Day Of Year (DOY) 205 the latent heat fluxes drop from a daily maximum around $200 \mathrm{~W} \cdot \mathrm{m}^{-2}$ to a value as low as $50 \mathrm{~W} \cdot \mathrm{m}^{-2}$. Wind conditions play a major role here. The first period of the campaign was characterized by winds between 1.5 and $3.0 \mathrm{~m} \cdot \mathrm{s}^{-1}$ for $90 \%$ of the time, whereas the second period daytime windspeed was higher than $5 \mathrm{~m} \cdot \mathrm{s}^{-1}$ during $90 \%$ of the time. Moreover, prevailing wind direction in the first period was from the north-west, whereas in the second period this was from the south-east. To the north of the vineyard a well-irrigated grassland was located, whereas to the east a large wheat stubble field existed. The observed fluxes in the first period may be partly influenced by the (wet) grassland, whereas during the second period the fluxes may be partly influenced by the (dry) wheat-stubble field. Detailed footprint analyses have to be carried out when a useful comparison between remote sensing-based and ground-based estimates of these fluxes has to be made (Timmermans et al. 2009).

\subsection{Data quality}

\section{Remote sensing data}

With respect to the space-borne data acquisitions, both the CHRIS as well as the MSG data are available at level 1 , meaning they consist of radiometrically calibrated and geo-located at-aperture radiances. However, no additional ground validation has been carried out yet for the space-borne observations.

The airborne data acquisitions are available at level 2, meaning they are radiometrically calibrated and geo-located hemispherical-directional reflectance factor and kinematic temperature. As for the AHS system, the radiometric calibration of the Visible and Near InfraRed (VNIR) and Shortwave InfraRed (SWIR) detectors is achieved illuminating the system with a uniform and known radiance source. The thermal infrared detectors, Middle InfraRed (MIR) and Thermal InfraRed (TIR), are calibrated by means of an extended black body source set at known temperature. Radiometric calibration of the detectors also provides Signal-Noise-Ratio (SNR) values, used to check if the system performance keeps within specified values. Channels 44 
and 46 had a very low Signal-to-Noise Ratio (SNR) due to detector malfunctioning; they should be used with reservations. Flight line AHS P11BD on 26 July shows a recording anomaly, which resulted in a small data gap.

For the CASI system, the radiometric calibration is achieved by illuminating the system with an integrating sphere. As with the AHS sensor, the radiometric calibration also provides SNR values which are used to check if the system performance keeps within specified values. For the high altitude flights column number 1441 is not valid. All CASI images suffer a slight spectral shift under flight conditions. A resampling of the input radiance from the estimated band centers to the reported band centers is performed before calibration. This procedure has a limited accuracy and might affect the radiometric accuracy in the absorption regions. The SNR for each band is reported in a statistics file, which should be checked before data analysis.

\section{In situ data}

The majority of the REFLEX 2012 in situ data has undergone standard postprocessing up to level 2, meaning they are available in geo-physical units that are calibrated and geo-located. The atmospheric in situ data and the radiometric and biophysical measurements are quality checked and the corresponding data are accompanied by metadata describing this.

With respect to the surface energy budget and micro-meteorological measurements, additional analysis was carried out on top of the standard post-processing and quality checking (van der Tol et al. 2015). Air temperature and humidity sensors from several sites were cross-calibrated versus each other which removed the bias and reduced relative errors induced by differences in sensor sensitivities by up to $90 \%$. Energy closure at the different sites was variable, ranging from $94 \%$ at the homogeneous camelina site to $67 \%$ for the vineyard site. A detailed analysis of the turbulent fluxes and the energy balance is provided in van der Tol et al. (2015).

\section{PRELIMINARY RESULTS AND RECOMMENDATIONS}

A complete overview of the airborne and in situ measurements of the REFLEX 2012 Campaign, designed to advance our understanding of landatmosphere exchanges of water and heat in space and time, is presented in this paper. Some preliminary analysis of the observational data is presented in some of the sections. The analysis included a near-surface atmospheric characterization and retrieval of a limited amount of biophysical variables. Envisaged advanced products include the following:

- land surface temperature and emissivity from AHS data,

口 emissivity from hyperspectral thermal in situ observations,

u intercomparison/cross-calibration of spectroscopy sensors, 
- monitoring of turbulence observations over multiple sites,

口 intercomparison of energy/water balance modeling schemes,

- thermal component derivation for multiple source energy flux estimates,

- estimation of evapotranspiration from airborne hyperspectral scanner data,

- photochemical reflectance index (PRI) as a water-stress index,

- soil moisture and surface emissivity over the heterogenous Barrax site.

Full details of several of the products above, and additional analyses, are reported elsewhere in this issue. As such, they represent current state-of-theart in the process understanding of land-atmosphere interactions and at the same time provide a base for expanding our understanding of these interactions.

Therefore, all data and all described advanced products that are obtained during and after the campaign are available via the REFLEX 2012 Campaign ftp site (ftp.uv.es/reflex/reflex database). The database is freely available to the scientific community and access can be acquired through a username and password which can be obtained by sending an email to w.j.timmermans@utwente.nl, or by contacting the individual authors directly.

Acknowledgements. The research leading to these results has received funding from the European Community's 7th Framework Programme (FP7/2008-2013) under EUFAR contract no. 227159, Cost Action ES0903EUROSPEC and ESA Grant D/EOP/rp/2012/48.

\section{References}

Foken, T. (2008), The energy balance closure problem: An overview, Ecol. Appl. 18, 6, 1351-1367, DOI: 10.1890/06-0922.1.

Gamon, J.A., C. Coburn, L.B. Flanagan, K.F. Huemmrich, C. Kiddle, G.A. SanchezAzofeifa, D.R. Thayer, L. Vescovo, D. Gianelle, D.A. Sims, A.F. Rahman, and G.Z. Pastorello (2010), SpecNet revisited: bridging flux and remote sensing communities, Can. J. Remote Sens. 36, Suppl. 2, 376-390, DOI: $10.5589 / \mathrm{m} 10-067$.

Gillespie, A., S. Rokugawa, T. Matsunaga, J.S. Cothern, S. Hook, and A.B. Kahle (1998), A temperature and emissivity separation algorithm for Advanced Spaceborne Thermal Emission and Reflection Radiometer (ASTER) images, IEEE T. Geosci. Remote Sens. 36, 4, 1113-1126, DOI: 10.1109/36. 700995. 
Kornelsen, K.C., and P. Coulibaly (2013), Advances in soil moisture retrieval from synthetic aperture radar and hydrological applications, J. Hydrol. 476, 460489, DOI: 10.1016/j.jhydrol.2012.10.044.

McCabe, M.F., and E.F. Wood (2006), Scale influences on the remote estimation of evapotranspiration using multiple satellite sensors, Remote Sens. Environ. 105, 4, 271-285, DOI: 10.1016/j.rse.2006.07.006.

Mishra, A.K., and V.P. Singh (2011), Drought modeling - A review, J. Hydrol. 403, 1-2, 157-175, DOI: 10.1016/j.hydrol.2011.03.049.

Novick, K., S. Brantley, C.F. Miniat, J. Walker, and J.M. Vosee (2014), Inferring the contribution of advection to total ecosystem scalar fluxes over a tall forest in complex terrain, Agr. Forest Meteorol. 185, 1-13, DOI: 10.1016/ j.agrformet.2013.10.010.

Prueger, J.H., J.G. Alfieri, L.E. Hipps, W.P. Kustas, J.L. Chavez, S.R. Evett, M.C. Anderson, A.N. French, C.M.U. Neale, L.G. McKee, J.L. Hatfield, T.A. Howell, and N. Agam (2012), Patch scale turbulence over dryland and irrigated surfaces in a semi-arid landscape under advective conditions during BEAREX08, Adv. Water Resour. 50, 106-119, DOI: 10.1016/ j.advwatres.2012.07.014.

Rast, M., J. Johannessen, and W. Mauser (2014), Review of understanding of Earth's hydrological cycle: Observations, theory and modelling, Surv. Geophys. 35, 3, 491-513, DOI: 10.1007/s10712-014-9279-x.

Rodell, M., P.R. Houser, U. Jambor, J. Gottschalck, K. Mitchell, C.-J. Meng, K. Arsenault, B. Cosgrove, J. Radakovich, M. Bosilovich, J.K. Entin, J.P. Walker, D. Lohmann, and D. Toll (2004), The global land and data assimilation system, Bull. Am. Meteorol. Soc. 85, 3, 381-394, DOI: 10.1175/BAMS-85-3-381.

Salama, M.S., R. van der Velde, H.J. van der Woerd, J.C. Kromkamp, C.J.M. Philippart, A.T. Joseph, P.E. O’Neill, R.H. Lang, T. Gish, P.J. Werdell, and Z. Su (2012), Technical note: Calibration and validation of geophysical observa-tion models, Biogeosciences 9, 2195-2201, DOI: 10.5194/bg-92195-2012.

Seneviratne, S.I., T. Corti, E.L. Davin, M. Hirschi, E.B. Jaeger, I. Lehner, B. Orlowsky, and A.J. Teuling (2010), Investigating soil moisture-climate interactions in a changing climate: A review, Earth Sci. Rev. 99, 3-4, 125-161, DOI: 10.1016/j.earscirev.2010.02.004.

Sobrino, J.A., J.C. Jiménez-Muñoz, P.J. Zarco-Tejada, G. Sepulcre-Cantó, E. de Miguel, G. Sòria, M. Romaguera, Y. Julien, J. Cuenca, V. Hidalgo, B. Franch, C. Mattar, L. Morales, A. Gillespie, D. Sabol, L. Balick, Z. Su, L. Jia, A. Gieske, W. Timmermans, A. Olioso, F. Nerry, L. Guanter, J. Moreno, and Q. Shen (2009), Thermal remote sensing from Airborne Hyperspectral Scanner data in the framework of the SPARC and SEN2FLEX projects: an overview, Hydrol. Earth Syst. Sci. 13, 2031-2037, DOI: 10.5194/hess-132031-2009. 
Su, Z., W.J. Timmermans, A. Gieske, L. Jia, J.A. Elbers, A. Olioso, J. Timmermans, R. van der Velde, X. Jin, H. van der Kwast, F. Nerry, D. Sabol, J.A. Sobrino, J. Moreno, and R. Bianchi (2008), Quantification of land-atmosphere exchanges of water, energy and carbon dioxide in space and time over the heterogeneous Barrax site, Int. J. Remote Sens. 29, 17-18, 5215-5235, DOI: 10.1080/01431160802326099.

Timmermans, J., Z. Su, C. van der Tol, A. Verhoef, and W. Verhoef (2013), Quantifying the uncertainty in estimates of surface-atmosphere fluxes through joint evaluation of the SEBS and SCOPE models, Hydrol. Earth Syst. Sci. 17, 1561-1573, DOI: 10.5194/hess-17-1561-2013.

Timmermans, W.J., G. Bertoldi, J.D. Albertson, A. Olioso, Z. Su, and A.S.M. Gieske (2008), Accounting for atmospheric boundary layer variability on flux estimation from RS observations, Int. J. Remote Sens. 29, 17-18, 52755290, DOI: 10.1080/01431160802036383.

Timmermans, W.J., Z. Su, and A. Olioso (2009), Footprint issues in scintillometry over heterogeneous landscapes, Hydrol. Earth Syst. Sci. 13, 2179-2190, DOI: $10.5194 /$ hess-13-2179-2009.

van der Tol, C. (2012), Validation of remote sensing of bare soil ground heat flux, Remote Sens. Environ. 121, 275-286, DOI: 10.1016/j.rse.2012.02.009.

van der Tol, C., W. Timmermans, C. Corbari, A. Carrara, J. Timmermans, and Z. Su (2015), An analysis of turbulent heat fluxes and the energy balance during the REFLEX campaign, Acta Geophys. 63, 6, 1516-1539, DOI: 10.1515/ acgeo-2015-0061 (this issue).

van Dijk, A.I.J.M., and L.J. Renzullo (2011), Water resource monitoring systems and the role of satellite observations, Hydrol. Earth Syst. Sci. 15, 39-55, DOI: 10.5194/hess-15-39-2011.

Wang, K., and R.E. Dickinson (2012), A review of global terrestrial evapotranspiration: Observation, modeling, climatology, and climatic variability, Rev. Geophys. 50, 2, RG2005, DOI: 10.1029/2011RG000373.

$\mathrm{Wu}, \mathrm{H}$., and Z.-L. Li (2009), Scale issues in remote sensing: A review on analysis, processing and modeling, Sensors 9, 3, 1768-1793, DOI: 10.3390/ s90301768.

Yebra, M., A. van Dijk, R. Leuning, A. Huete, and J.P. Guerschman (2013), Evaluation of optical remote sensing to estimate actual evapotranspiration and canopy conductance, Remote Sens. Environ. 129, 250-261, DOI: 10.1016/j.rse.2012.11.004.

Received 22 October 2013 Received in revised form 19 August 2014 Accepted 26 September 2014 